\title{
Significant Caries Index: A Better Indicator for Dental Caries
}

\author{
Rupsa Banerjee ${ }^{1}$, Bratati Banerjee $^{2^{*}}$
}

\section{Rupsa Banerjee', Bratati Banerjee $^{2^{*}}$}

'Department of Community Medicine, Vardhman Mahavir Medical College and Safdarjung Hospital, New Delhi, India.

${ }^{2}$ Department of Community Medicine, Maulana Azad Medical College, New Delhi, India

\section{Correspondence}

Dr. Bratati Banerjee,

DNB, Professor, Department of Community Medicine, Maulana Azad Medical College, New Delhi- 110002, India.

Phone no: +91-9968604251

Email: bratati1@hotmail.com

History

- Submission Date: 22-01-19

- Revised Date: 29-04-19

- Accepted Date: 21-05-19

DOI : 10.5530/ijmedph.2019.2.15

Article Available online http://www.ijmedph.org/v9/i2

\section{Copyright}

(C) 2019 Phcog.Net. This is an openaccess article distributed under the terms of the Creative Commons Attribution 4.0 International license.
Sir,

Dental caries is one of the oro-dental diseases which is highly prevalent in India. ${ }^{1,2}$ DMFT index has been widely used to assess the caries status among individuals by computing the mean number of Decayed (D), Missing (M) and Filled (F) teeth in a population. This index however does not reflect the true picture since there are both individuals with considerably higher DMFT values as well as caries-free individuals in the same population. Significant Caries index $(\mathrm{SiC})$ is a better indicator in this case because it records the individuals with the highest DMFT values. The Global Goals for Oral Health in the year 2000 proposed to reduce the $\mathrm{SiC}$ index among the 12 -year-olds to less than 3 DMFT by the year 2015, globally.

The present study was done as a part of the School Health Programme in selected government schools in south Bangalore where students of classes 1 to 10 were examined as part of annual health check-up which included dental examination and questions on oral hygiene habits. DMFT score for permanent teeth and $\mathrm{dmft}$ score for temporary teeth were calculated for each child. SiC index was calculated, according to the WHO formula, ${ }^{3}$ for the 12 -year-old population by calculating the average DMFT score of one third of the 12-year old children having the highest DMFT values, to assess whether this was in line with the proposed global goals for oral health.

A total of 526 children aged 6 to 16 years were included in the study among whom the prevalence of dental caries was found to be $38.59 \%$. Dental caries was found to be significantly greater in girls (47.41\%) than boys $(31.63 \%)$ at $p<0.001$. Prevalence of dental caries was significantly lower among children who brushed twice a day or more $(26.83 \%)$ than among those who brushed lesser number of times (62.79\%) at $p<0.001$. The mean DMFT and DMFT scores for the study population were $1.95 \pm 0.92$ and $2.29 \pm 1.51$ respectively. Among the study population there were 144 children who were 12 years of age and the mean decayed, missing and filled teeth score among these children was $2.56 \pm 1.13$ whereas their Significant Caries index $(\mathrm{SiC})$ was 3.72 , which was higher than their mean DMFT score and also higher than the proposed goal of 3 DMFT. Findings of other studies previously conducted were also in agreement with those of the present study.,4-6

In any population there is a skewed distribution of caries prevalence, i.e., there are individuals with high caries scores whereas a large part of the population is caries-free. Significant Caries Index is more accurate in assessing the caries morbidity since it takes into account a third of the individuals with highest caries scores whereas the mean decayed, missing and filled teeth score usually camouflage the real picture leading to the incorrect conclusion that the caries situation for the whole population is controlled. The National School Health Programme provides a good opportunity for promotion of oral health and screening for dental morbidities. In conclusion, dental caries was prevalent among the school children in the present study, with a high Significant Caries Index among the 12-year old children.

\section{REFERENCES}

1. MOHFW. Operational Guidelines National Oral Health Programme 2012-17. National Oral Health Cell, DGHS, Ministry of Health \& Family Welfare, New Delhi.

2. Kulkarni SS, Deshpande SD. Caries prevalence and treatment needs in 11-15 year old children of Belgaum city. $J$ Indian Soc Pedodo Prev Dent 2002;20(1):12-15.

3. Nishi M, Bratthall D, Stjernsward J. How to calculate the Significant Caries Index (SiC index). Sweden; 2001. [Cited 2019 May 2] Available at https://www.mah.se/upload/ fakulteter/od/Avdelningar/who/MetodsIndices/SIC/data/ significant.pdf.

4. Murugan RV, Sakthi S. Dental caries experience and treatment needs among 12-year-old school children in Chennai, Tamil Nadu. Int J Child Health 2016;3(2):163-6.

5. Limbu S, Dikshit P, Bhagat T. Evaluation of dental caries among preschool children in Kathmandu using significant caries index. J Nepal Med Assoc 2017;56(207):341-5.

6. Bhagat TK, Shrestha A. Dental caries experience among school children of Eastern Nepal - significant caries index. Health Renaissance 2014;12(2):74-7. 